ARTICLE

Received 18 Jan 2017 | Accepted 10 Apr 2017 | Published 19 May $2017 \quad$ DOl: 10.1038/ncomms15581

\title{
Mesoporous metallic rhodium nanoparticles
}

Bo Jiang ${ }^{1,2}$, Cuiling Li ${ }^{1}$, Ömer Dag ${ }^{3}$, Hideki Abe ${ }^{1}$, Toshiaki Takei ${ }^{1}$,Tsubasa Imai ${ }^{1}$, Md. Shahriar A. Hossain 1,4, Md. Tofazzal Islam ${ }^{5}$, Kathleen Wood ${ }^{6}$, Joel Henzie ${ }^{1} \&$ Yusuke Yamauchi ${ }^{1,2,4}$

Mesoporous noble metals are an emerging class of cutting-edge nanostructured catalysts due to their abundant exposed active sites and highly accessible surfaces. Although various noble metal (e.g. Pt, Pd and Au) structures have been synthesized by hard- and soft-templating methods, mesoporous rhodium (Rh) nanoparticles have never been generated via chemical reduction, in part due to the relatively high surface energy of rhodium (Rh) metal. Here we describe a simple, scalable route to generate mesoporous Rh by chemical reduction on polymeric micelle templates [poly(ethylene oxide)-b-poly(methyl methacrylate) (PEO-b-PMMA)]. The mesoporous Rh nanoparticles exhibited a $\sim 2.6$ times enhancement for the electrocatalytic oxidation of methanol compared to commercially available Rh catalyst. Surprisingly, the high surface area mesoporous structure of the Rh catalyst was thermally stable up to $400^{\circ} \mathrm{C}$. The combination of high surface area and thermal stability also enables superior catalytic activity for the remediation of nitric oxide (NO) in lean-burn exhaust containing high concentrations of $\mathrm{O}_{2}$.

\footnotetext{
${ }^{1}$ International Center for Materials Nanoarchitectonics (MANA), National Institute for Materials Science (NIMS), 1-1 Namiki, Tsukuba, Ibaraki 305-0044, Japan. ${ }^{2}$ Faculty of Science and Engineering, Waseda University, 3-4-1 Okubo, Shinjuku, Tokyo 169-8555, Japan. ${ }^{3}$ Department of Chemistry, Bilkent University, 06800 Ankara, Turkey. ${ }^{4}$ Australian Institute for Innovative Materials (AlIM), University of Wollongong (UOW), Squires Way, North Wollongong, New South Wales 2500, Australia. ${ }^{5}$ Department of Biotechnology, Bangabandhu Sheikh Mujibur Rahman Agricultural University, Gazipur 1706, Bangladesh. ${ }^{6}$ Australian Nuclear Science and Technology Organisation (ANSTO), New Illawarra Rd, Lucas Heights, New South Wales 2234, Australia. Correspondence and requests for materials should be addressed to Y.Y. (email: yusuke@uow.edu.au).
} 
T he creation of well-controlled nanomaterial architectures is critical for more efficient utilization of rare metals and also enables unique chemical and physical properties that are not evident in bulk ${ }^{1-3}$. Making mesoporous frameworks composed of carbon ${ }^{4-7}$, metal oxides ${ }^{8,9}$, silica ${ }^{10-13}$, polymers $^{14-16}$ and metals ${ }^{17-19}$ has led to enhanced performance in catalysis ${ }^{20,21}$, energy conversion and storage ${ }^{22,23}$, surface-enhanced Raman spectroscopy (SERS) ${ }^{24,25}$ and chemical/biochemical sensing ${ }^{26}$. In particular, the application of mesoporous noble metals in the field of heterogeneous catalysis has distinct and numerous advantages in terms of performance. These mesoporous metal architectures expose abundant catalytically active sites due to their high specific surface areas and accessible porous structures. The inherent conductivity of the metal maximizes the rate of electron transfer inside a porous network, helping to facilitate mass transfer throughout the entire structure $^{27,28}$. Growing metals inside sacrificial hard-templates (for example, mesoporous silica) has mostly been used to synthesize mesoporous metal structures ${ }^{29,30}$. Recently, lyotropic liquid crystals (LLC) composed of surfactants or block polymers were used as soft templates to grow mesoporous metals (e.g. Pt, Pd, Ni, Rh and Sn) ${ }^{1,31-33}$. Yet the flexibility of the LLC approach is limited due to the high viscosity of the solvent system, and there have been few reports describing the successful synthesis of mesoporous rhodium (Rh) catalysts thus far. Simplifying the synthesis of mesoporous $\mathrm{Rh}$ would expand the materials palette for mesoporous noble metal chemistry and enable more efficient utilization of rare metals in catalysis.

Nanostructured $\mathrm{Rh}$ is ubiquitous in heterogeneous catalysis, playing a huge role in the refinement of petroleum, the production of fine chemicals and energy generation via fuel cell technology ${ }^{34-37}$. Increasing surface area has been a common strategy to improve the performance of catalysts ${ }^{38}$. Advances in synthetic colloidal methods, combined with access to advanced structural characterization tools, has enabled the deliberate engineering of surface atoms, including their degree of coordination, and the presence of structural defects ${ }^{39,40}$. Making nano-sized $\mathrm{Rh}$ materials should similarly enable a higher level of control over surface structure. For example, Yu et al. has shown that the convex Rh nanocrystals bound by $\{830\}$ facets exhibit higher activity for ethanol electro-oxidation than irregular Rh nanoparticles, as well as commercial Rh black ${ }^{41}$. Huang and co-authors pointed out that wavy $\mathrm{Rh}$ nanowires have numerous structural defects/grain boundaries that are responsible for high catalytic activity ${ }^{42}$. Additionally, two-dimensional (2D) $\mathrm{Rh}$ nanosheets with exposed $\mathrm{Rh}$ atoms in ultrathin layered nanostructures perform well in hydrogenation reactions ${ }^{43}$. Although the precise nature of the $\mathrm{Rh}$ active site is not well understood, the impact of crystallographic features (for example, atomic steps, corners and defects) induced by well-designed nanostructures can boost performance in numerous catalytic reactions ${ }^{41-44}$. Therefore, the synthesis of mesoporous $\mathrm{Rh}$ structures should be another effective way to further increase surface area and catalytic active sites while pushing the limits of material utilization beyond what can be achieved with existing Rh-based nanostructures (that is, nanoparticles, nanowires and so on).

The surface energy of $\mathrm{Rh}$ is notably larger than other noble metals including $\mathrm{Pt}, \mathrm{Au}$ and $\mathrm{Pd}^{45}$. Thus generating high surface area $\mathrm{Rh}$ nanostructures at mild conditions is extremely challenging synthetically because the equilibrium shape of $\mathrm{Rh}$ and other FCC metals tends to minimize surface area and is dominated by low index facets ${ }^{46}$. Therefore, a successful synthesis of mesoporous Rh will likely need to be controlled by a kinetic mechanism. Here we describe the synthesis of a nanostructured $\mathrm{Rh}$ catalyst and examine how the mesoporous structure impacts its catalytic properties. The synthesis of $\mathrm{Rh}$ mesoporous nanoparticles is realized using chemical reduction of a $\mathrm{Rh}$
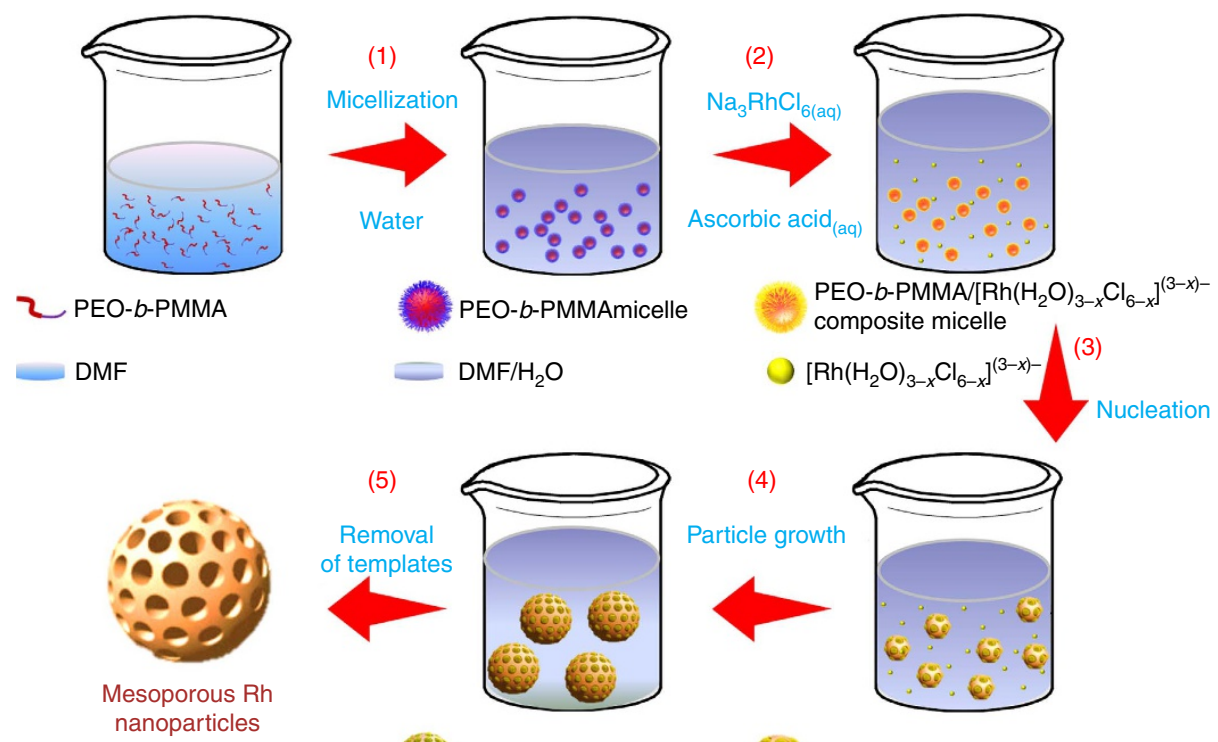

Mesostructured Rh

Mesostructured Rh (initial stage)

Figure 1 | An illustration describing the formation mechanism for mesoporous Rh nanostructures. Mesoporous Rh nanostructures form via chemical

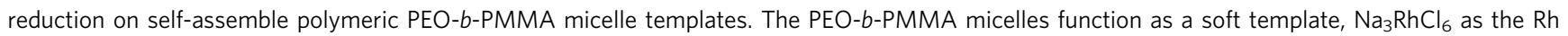
precursor, $\mathrm{AA}$ as the reducing agent, and $\mathrm{DMF} / \mathrm{H}_{2} \mathrm{O}$ as the mixed solvent, respectively. The synthetic process has five steps; (1) addition of water causes the PEO- $b$-PMMA to self-assemble into spherical micelles with a PMMA core and a PEO shell, $(2) \mathrm{Na}_{3} \mathrm{RhCl}_{6}$ source is dissolved into $\mathrm{Na}^{+}$and $\left[\mathrm{Rh}\left(\mathrm{H}_{2} \mathrm{O}\right)_{3}\right.$ $\left.{ }_{x} \mathrm{Cl}_{6-x}\right]^{(3-x)}-$ and then the aqua-complexes interact with the PEO moieties via hydrogen bonding between the PEO and aqua-complexes (that is, the formation of PEO- $b-\mathrm{PMMA} /\left[\mathrm{Rh}\left(\mathrm{H}_{2} \mathrm{O}\right)_{3-x} \mathrm{Cl}_{6-x}\right]^{(3-x)}-$ composite micelles), (3) the Rh species are reduced to form solid Rh nuclei, (4) which coalesce and further grow into mesoporous Rh nanostructures over and (5) the templates are removed by a solvent extraction method. 
precursor salt on sacrificial polymeric micelle templates. Construction of accessible $3 \mathrm{D}$ mesoporous networks in $\mathrm{Rh}$ metal maximizes the material utilization of $\mathrm{Rh}$ and simultaneously enables the creation of numerous active sites for enhanced catalytic activity.

\section{Results}

Synthesis of mesoporous $\mathrm{Rh}$ nanoparticles. A schematic diagram illustrates the wet chemical synthesis of mesoporous $\mathrm{Rh}$ nanoparticles (Fig. 1). A block polymer poly(ethylene oxide)- $b$-poly(methyl methacrylate) $\left(\mathrm{PEO}_{10500}-b\right.$ - $\left.\mathrm{PMMA}_{18000}\right)$ is used as a template, while water and $\mathrm{N}, \mathrm{N}$-dimethylformamide (DMF) are used as the mixed solvent, and $\mathrm{Na}_{3} \mathrm{RhCl}_{6}$ and ascorbic acid (AA) were selected as metal precursor and reducing agent, respectively. After chemical reduction, the mesoporous $\mathrm{Rh}$ nanoparticles were successfully generated via assembly of polymeric micelles (see Methods). After consecutive washing/centrifugation cycles with an appropriate solvent, the product had a nearly clean surface (Supplementary Fig. 1).

The shape and mesoporous structure of the sample were initially characterized by scanning electron microscopy (SEM) and transmission electron microscopy (TEM) (Fig. 2). According to SEM micrographs, the nanoparticles are highly dispersed with uniformity in both shape and size (Fig. 2a). The average diameter of the nanoparticles was estimated to be $\sim 100 \mathrm{~nm}$ by analysing $>200$ nanoparticles (Supplementary Fig. 2). SEM shows welldefined mesostructures with large-sized pores distributed throughout the entire outer surface of the nanoparticles (Fig. 2b). Closer inspection using high-angle annular dark-field scanning TEM (HAADF-TEM) shows a pattern of contrast that indicates the mesopores are distributed throughout the interior of the nanoparticles (Fig. 2d). The selected area electron diffraction (SAED) patterns of single particles show concentric rings of spots, indicating the particles are polycrystalline (Supplementary Fig. 3a,b). But closer examination with high-resolution TEM (HRTEM) shows that the local structure around the pore walls is highly crystalline, with $0.20 \mathrm{~nm}$ lattice fringes that correspond to the (111) plane of the face-centered cubic (fcc) Rh crystal (Supplementary Fig. 3c,d). Surprisingly, some atomic steps and kink sites typically associated with unsaturated coordination atoms could be observed on the branched structure. Presence of these structures is a good initial sign that these materials will have excellent performance in catalysis.

Low-angle X-ray diffraction measurements were used here to determine the periodicity (that is, pore-to-pore distance) of the final mesoporous structure. A single peak located at $0.43^{\circ}$ was observed in the X-ray diffraction pattern, showing the pores are uniform in size and closely packed (Supplementary Fig. 4a). On the basis of centre of the peak, the calculated pore-to-pore distance was $\sim 21 \mathrm{~nm}$. Considering the pore size $(\sim 11 \mathrm{~nm}$ via SEM, Fig. 2b), the thickness of the pore wall was estimated to be $\sim 10 \mathrm{~nm}$. The wide-angle X-ray diffraction pattern of the sample displays five characteristic diffraction peaks of the $\mathrm{Rh}$ (111), (200), (220), (311) and (222), respectively (Supplementary Fig. 4b). No other impurities or rhodium oxide diffraction peaks were detected in the X-ray diffraction patterns, suggesting the particle is purely metallic. The average grain size is $\sim 4.2 \mathrm{~nm}$ according to the Scherrer equation, which we assume is roughly the average size of the sub-particles within the mesoporous networks. The electronic state of Rh surface is also confirmed by X-ray photoelectron spectroscopy (XPS) analysis (Supplementary Fig. 1b). Nitrogen $\left(\mathrm{N}_{2}\right)$ adsorption-desorption isotherms demonstrate the sample has a large surface area of ca. $50 \mathrm{~m}^{2} \mathrm{~g}^{-1}$ (Supplementary Fig. 4c). The surface area value is within a reasonable range for mesoporous materials with large mesopores $(>10 \mathrm{~nm})$, as shown in Supplementary Table 1. The pore size distribution diagram (Supplementary Fig. 4d) clearly shows the presence of mesopores (around $9 \mathrm{~nm}$ ) originating from the removal of polymeric micelles.

Our approach for the synthesis of mesoporous Rh nanoparticles is based on the chemical reduction of $\mathrm{Rh}$ precursor in the presence of a polymeric micelle network (Fig. 1). This network
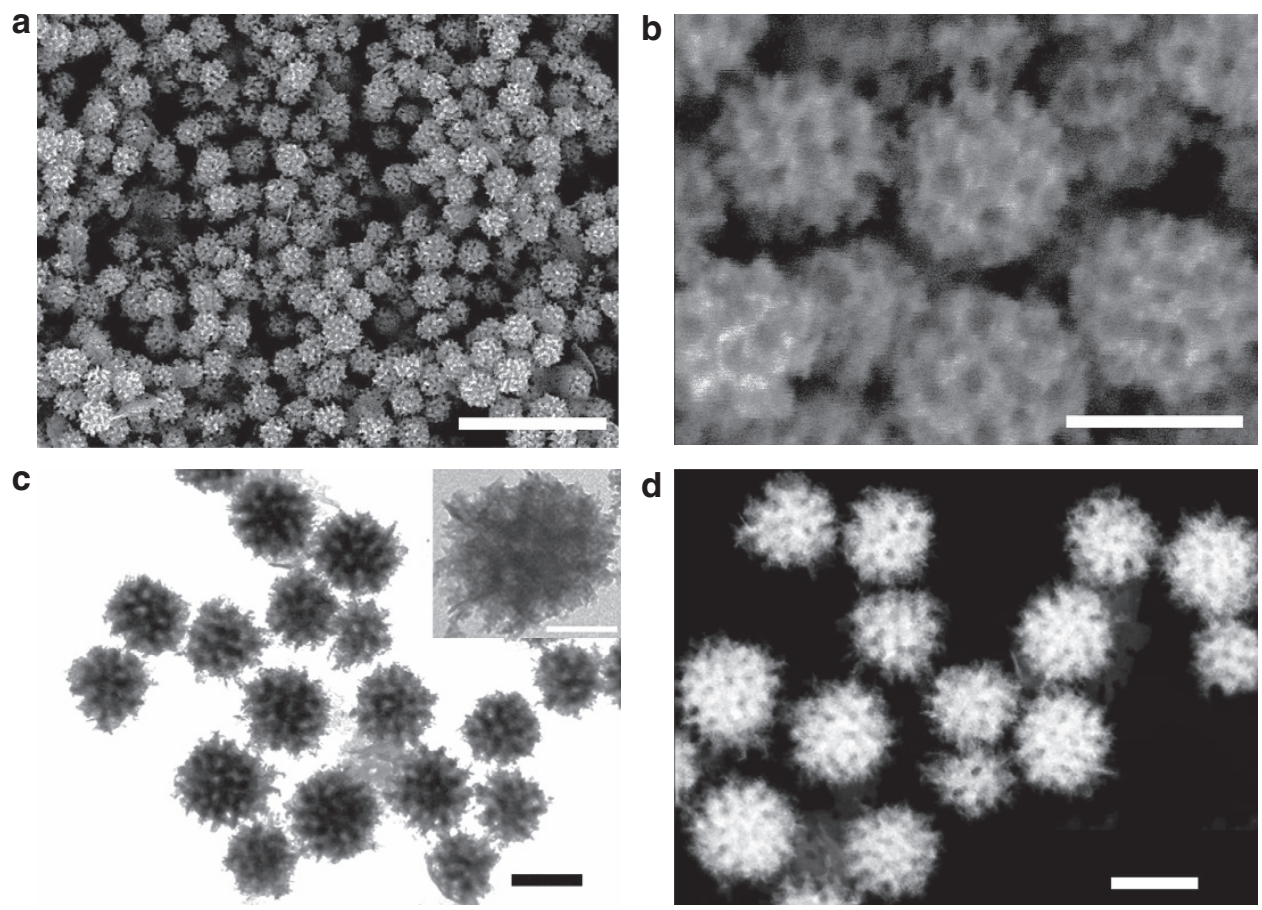

Figure 2 | Structural characterization of mesoporous Rh nanoparticles. (a) Low-magnification SEM micrograph (Scale bar, $500 \mathrm{~nm}$ ), (b) high-magnification SEM micrograph (Scale bar, $100 \mathrm{~nm}$ ), (c) TEM micrograph (Scale bar, $100 \mathrm{~nm}$ ) and (d) HAADF-STEM micrograph (Scale bar, $100 \mathrm{~nm}$ ) of mesoporous Rh nanoparticles. The inset in $\mathbf{c}$ is a high-magnification TEM micrograph of a single mesoporous Rh nanoparticle (Scale bar, $50 \mathrm{~nm}$ ). 
functions as a pore-directing agent and template that directs the formation of uniformly sized mesoporous nanoparticles. In pure DMF, the block polymer PEO- $b$-PMMA is completely dissolved as a unimer because of the good solubility of hydrophilic PEO and hydrophobic PMMA segments. Adding deionized water and various aqueous precursor solutions (that is, $\mathrm{Na}_{3} \mathrm{RhCl}_{6(\mathrm{aq})}$ and $\mathrm{AA}_{(\mathrm{aq})}$ ) decreases the solvation of the hydrophobic PMMA segments, leading to the formation of spherical micelles composed of a PMMA core surrounded by a PEO shell. The presence of micelles in solution is clearly illustrated by the Tyndall effect (Supplementary Fig. 5). Small-angle neutron scattering (SANS) was also performed to characterize the micelles in solution (Fig. 3a). The polymeric micelles are relatively monodisperse in solution as displayed by the linear Guinier region at low $\mathrm{Q}$. The radii of gyration of the scattering particles were extracted from the Guinier fits and found to be $100 \AA$ for the sample (Supplementary Fig. 6). Real space radii of gyration extracted from probability distribution functions agree within error to those given by the Guinier fits. In order to directly visualize the micelle structure, polymeric micelles were stained with phosphotungstic acid and further studied by TEM. The bright spheres correspond to the PMMA micellar cores (lower electron density region) due to the negative staining by phosphotungstic acid (Fig. 3b,c and Supplementary Fig. 7). After addition of $\mathrm{Na}_{3} \mathrm{RhCl}_{6}$, no significant changes on the micelle shape were observed from the TEM micrographs, showing the presence of $\mathrm{Na}_{3} \mathrm{RhCl}_{6}$ precursor did not destroy the micelle structure. The average micelle size obtained by SANS $(\sim 20 \mathrm{~nm})$ is larger than the size of PMMA micellar cores in TEM due to micelle shrinkage at high vacuum.

Applications. The catalytic activity for the methanol oxidation reaction (MOR) was investigated electrochemically. The peak current density is conventionally used to evaluate catalytic activity for MOR. In Supplementary Fig. 8, clear features of the hydrogen adsorption/desorption could be observed in the low potential region on both the mesoporous $\mathrm{Rh}$ and commercial $\mathrm{Rh}$ black $(\mathrm{Rh} / \mathrm{B})$ catalysts, indicating the cleanliness of the catalyst surface. For the $\mathrm{CO}$ stripping reaction in $0.5 \mathrm{M} \mathrm{H}_{2} \mathrm{SO}_{4}$, linear sweep voltammetry (LSV) was used to oxidize monolayer $\mathrm{CO}$ adsorbed on the $\mathrm{Rh}$ surface, yielding a characteristic $\mathrm{CO}$ oxidation peak on both the mesoporous Rh and Rh/B (Fig. 4a). The mesoporous $\mathrm{Rh}$ nanoparticles have a more negative onset potential and peak potential for $\mathrm{CO}$ oxidation than $\mathrm{Rh} / \mathrm{B}$. This result demonstrates that the mesoporous $\mathrm{Rh}$ nanoparticles are better at $\mathrm{CO}$ oxidation than $\mathrm{Rh} / \mathrm{B}$ probably due to higher activity for $\mathrm{CO}$ stripping on the curved surface of Rh (Supplementary Fig. $3 \mathrm{c}, \mathrm{d}$ ) ${ }^{47,48}$. Figure $4 \mathrm{~b}$ shows typical cyclic voltammetric curves for MOR catalysed by the two catalysts in $1 \mathrm{M} \mathrm{KOH}$ solution containing $1 \mathrm{M}$ methanol at a scan rate of $50 \mathrm{mV} \mathrm{s}^{-1}$. The mesoporous $\mathrm{Rh}$ nanoparticles exhibited a mass activity of $288 \mathrm{~mA} \mathrm{mg}^{-1}$ in the forward sweep, which is up to 2.6 times greater than $\mathrm{Rh} / \mathrm{B}$ catalyst $\left(110 \mathrm{~mA} \mathrm{mg}^{-1}\right)$, demonstrating the higher utilization
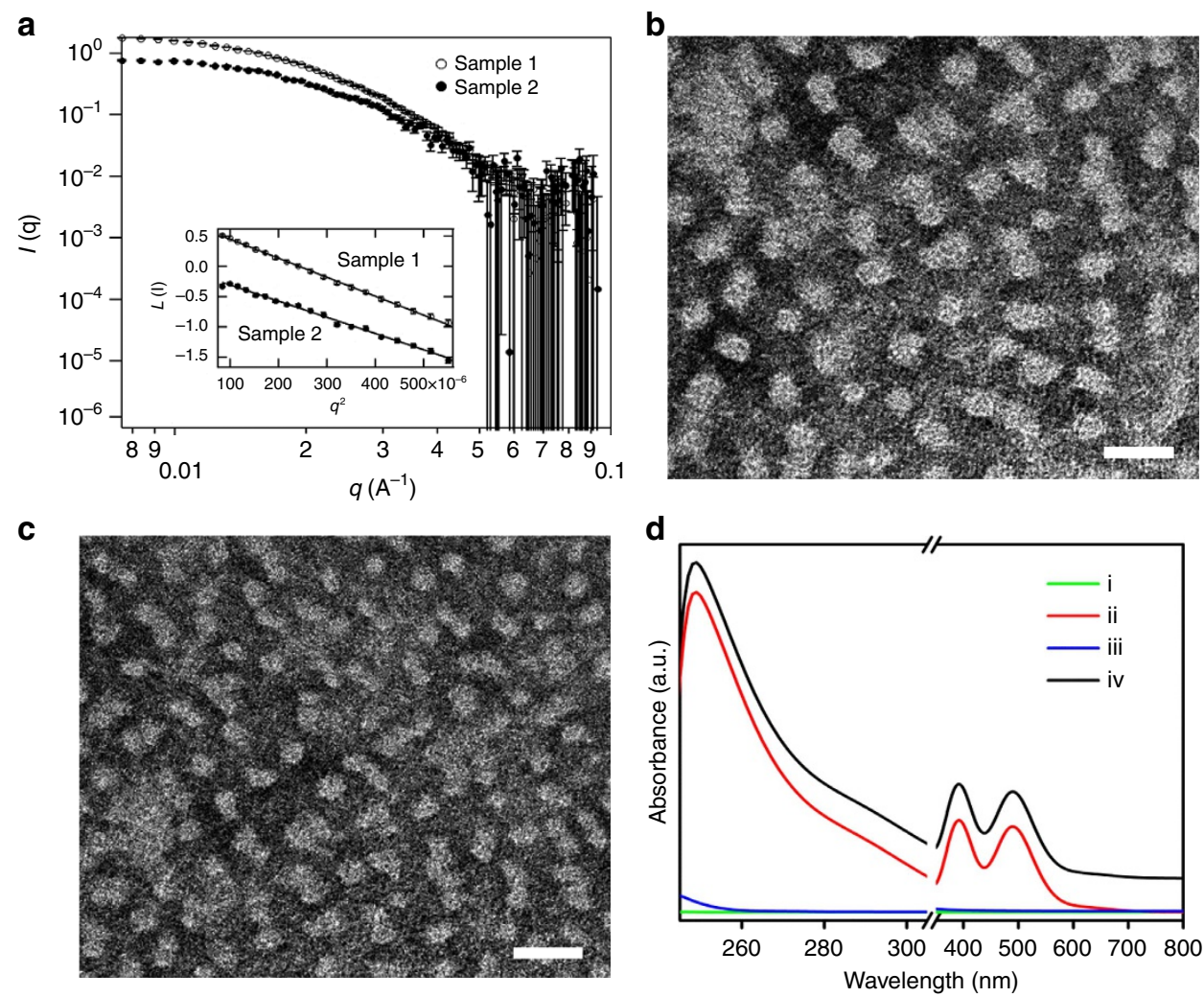

Figure 3 | Characterization of polymeric micelles. (a) Small-angle neutron scattering (SANS) patterns of two types of polymeric micelle solutions with

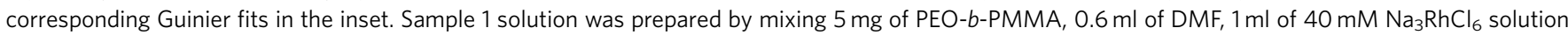
in $\mathrm{H}_{2} \mathrm{O}$, and $1.4 \mathrm{ml} \mathrm{D} 2 \mathrm{O}$, while Sample 2 was prepared by mixing $5 \mathrm{mg}$ of PEO-b-PMMA, $0.6 \mathrm{ml}$ of DMF, and $1 \mathrm{ml}$ of $40 \mathrm{mM} \mathrm{Na}_{3} \mathrm{RhCl}_{6}$ solution. (b,c) Typical TEM micrographs showing the polymeric micelles (b) before and (c) after the addition of $\mathrm{Na}_{3} \mathrm{RhCl}_{6}$ precursor (Scale bar, $50 \mathrm{~nm}$ ). The polymeric micelles are stained with $1.0 \mathrm{wt} \%$ phosphotungstic acid. (d) UV-VIS-NIR spectra of different solutions: (i) DMF + Water, (ii) $\mathrm{DMF}^{+} \mathrm{Water}+\mathrm{Na}_{3} \mathrm{RhCl} \mathrm{\sigma}_{6}$ (iii) $\mathrm{DMF}+$ Water + PEO-b-PMMA and (iv) DMF + Water + PEO-b-PMMA + $\mathrm{Na}_{3} \mathrm{RhCl}_{6}$, respectively. [Note: to highlight the interactions among different compositions, UV-VIS-NIR spectra of low- and high- wavelengths were obtained at different composition concentrations: low concentration for lowwavelength, and high concentration for high-wavelength]. 

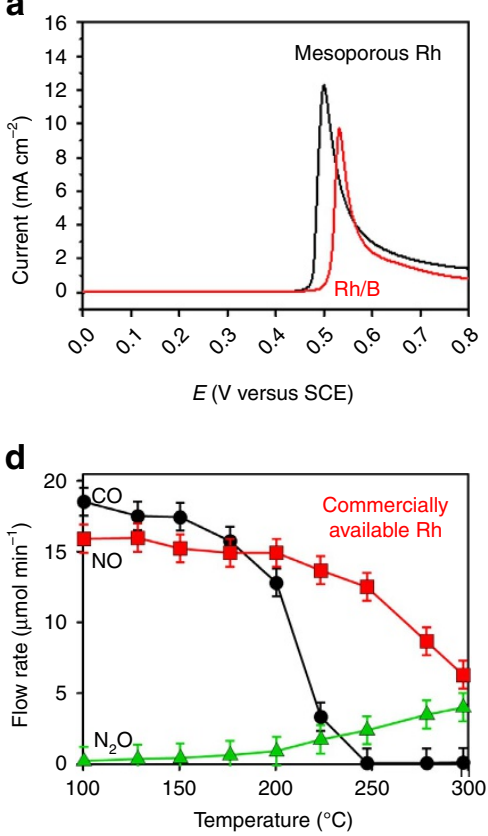

b

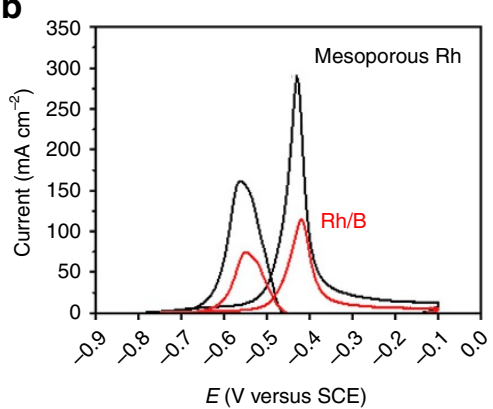

e

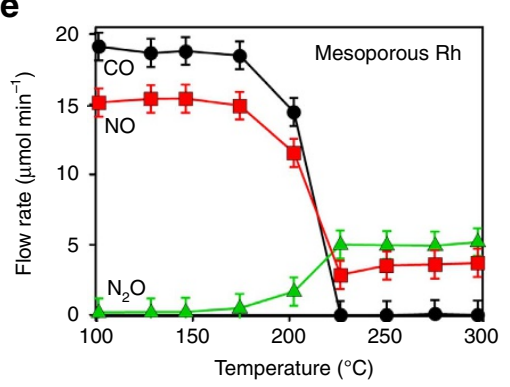

C

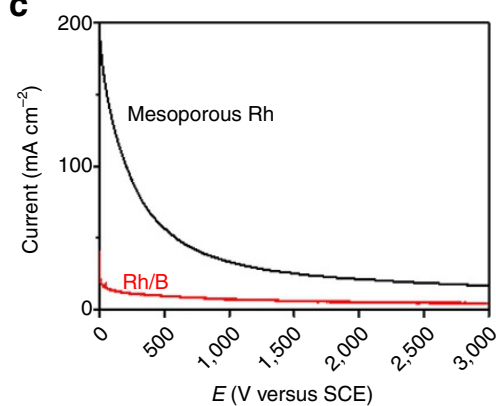

$\mathbf{f}$

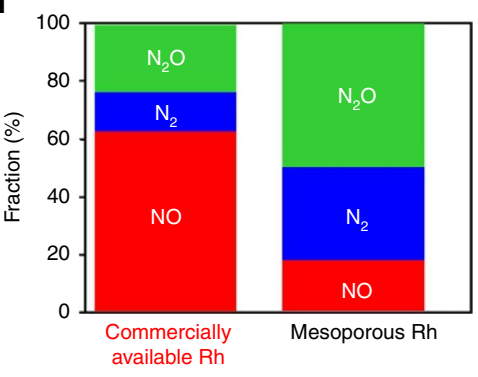

Figure 4 | Application of mesoporous Rh nanoparticles. (a) Linear sweep voltammograms (LSV) of CO oxidation in $0.5 \mathrm{M} \mathrm{H}_{2} \mathrm{SO}_{4}$ solution and (b) $\mathrm{CV}$ curves of mesoporous $\mathrm{Rh}$ nanoparticles and $\mathrm{Rh} / \mathrm{B}$ in $1 \mathrm{M} \mathrm{KOH}+1 \mathrm{M} \mathrm{CH}_{3} \mathrm{OH}$ solution at $50 \mathrm{mVs}^{-1}$. (c) Chronoamperometric curves of mesoporous Rh nanoparticles and $\mathrm{Rh} / \mathrm{B}$ in $1 \mathrm{M} \mathrm{KOH}+1 \mathrm{M} \mathrm{CH}_{3} \mathrm{OH}$ solution at $-0.4 \mathrm{~V}$. (d,e) The volume fractions of $\mathrm{CO}, \mathrm{NO}$ and $\mathrm{N}_{2} \mathrm{O}$ in the effluent gas passing through (d) the commercially available $\mathrm{Al}_{2} \mathrm{O}_{3}$-supported $\mathrm{Rh}$ catalyst $\left(\mathrm{Rh} / \mathrm{Al}_{2} \mathrm{O}_{3}\right.$ ) and (e) the mesoporous $\mathrm{Rh}$ nanoparticles at different temperatures. (f) Volume fraction of $\mathrm{NO}$ (red), $\mathrm{N}_{2}$ (blue) and $\mathrm{N}_{2} \mathrm{O}$ gas in the effluent gas at $250^{\circ} \mathrm{C}$.

efficiency of $\mathrm{Rh}$ metal in the mesoporous structures. The chronoamperometric curve (Fig. 4c) recorded at $-0.4 \mathrm{~V}$ under the same conditions for MOR show that the mesoporous $\mathrm{Rh}$ nanoparticles had a slower current decay, because mesoporous structures are known to be less vulnerable to aggregation ${ }^{49,50}$.

Generally, structural thermostability is a very important factor for practical catalysts. For reactions that occur at relatively high temperatures, it is critical that the catalysts are able to retain their shape and structure. To study the thermostability of mesoporous $\mathrm{Rh}$, the samples were calcined at different temperatures (for example, $250,300,350$ and $400^{\circ} \mathrm{C}$ ) for $1 \mathrm{~h}$ in $\mathrm{N}_{2}$ or air atmosphere. No obvious changes in the mesoporous structure or particle aggregation could be observed in the SEM micrographs even after thermal treatment at $400{ }^{\circ} \mathrm{C}$ in either atmosphere (Supplementary Figs 9 and 10). The low-angle X-ray diffraction profiles are unchanged even after thermal treatment, showing that calcination at high temperatures did not result in the collapse of mesoporous structure (Supplementary Fig. 11). These results indicate that the mesoporous $\mathrm{Rh}$ nanoparticles are stable at relatively high temperatures. Supplementary Fig. 12a shows wide-angle X-ray diffraction patterns indicating that the $\mathrm{Rh}$ is partially oxidized when the sample was calcined in air. This result was supported by TGDTA analysis (Supplementary Fig. 12c). However, no oxidized Rh could be observed by X-ray diffraction when the sample was calcined under $\mathrm{N}_{2}$ atmosphere (Supplementary Fig. 12b,d). With increasing temperatures, each crystal gradually merged, causing the average size of the Rh nanoparticles to increase slightly from $c a$. $4.2 \mathrm{~nm}$ to $c a .5 .9 \mathrm{~nm}$ (for $250^{\circ} \mathrm{C}$ ), ca. $6.2 \mathrm{~nm}$ (for $300^{\circ} \mathrm{C}$ ), ca. $6.8 \mathrm{~nm}$ (for $350^{\circ} \mathrm{C}$ ) and ca. $7.0 \mathrm{~nm}$ (for $400^{\circ} \mathrm{C}$ ), respectively, under $\mathrm{N}_{2}$ atmosphere. After the calcination at $400{ }^{\circ} \mathrm{C}$, the average crystal size was at most $c a .7 .0 \mathrm{~nm}$ which is less than the thickness of the pore walls. Such merging and rearrangement of crystals inside the frameworks did not affect the mesoporous architecture. Heating the structures above $450^{\circ} \mathrm{C}$ in $\mathrm{N}_{2}$ caused the average crystal size to increase $(c a .26 .9 \mathrm{~nm})$ beyond the original thickness of the pore walls, destroying the original mesoporous structure (Supplementary Fig. 10e).

Although transition-metal oxides have been investigated for several decades as an alternative material for nitric oxide (NO)-remediation ${ }^{51}$, they are susceptible to rapid degradation by catalytic poisoning by $\mathrm{O}_{2}$ contained in the exhaust ${ }^{52}$. We evaluated the performance of the mesoporous $\mathrm{Rh}$ and commercially available $\mathrm{Al}_{2} \mathrm{O}_{3}$-supported $\mathrm{Rh}$ nanoparticles (2-3 nm $\mathrm{Rh}$ nanoparticles) ( $\mathrm{Rh} / \mathrm{Al}_{2} \mathrm{O}_{3} ;$ Aldrich, $\mathrm{Rh}$ loading $=5 \mathrm{wt} \%$ ) (Supplementary Fig. 13) for the remediation of automobile exhaust under lean-burn conditions (Fig. 4d,e). Each catalyst was subjected to a steady stream of simulated lean-burn exhaust containing nitrogen monoxide (NO), oxygen $\left(\mathrm{O}_{2}\right)$, carbon monoxide (CO) and $\mathrm{Ar}$ gas (volume ratio $=\mathrm{NO}: \mathrm{O}_{2}: \mathrm{CO}: \mathrm{Ar}=1: 0.5: 1: 97.5 ;$ space velocity $=30,000$ per $1 \mathrm{~h})$ at different temperatures from room temperature to $300^{\circ} \mathrm{C}$. Figure $4 \mathrm{~d}$ shows that the $\mathrm{CO}$ fraction in the effluent gas decreased with increasing temperature and vanished at $250^{\circ} \mathrm{C}$ due to the catalytic oxidation by $\mathrm{NO}$ and/or $\mathrm{O}_{2}$ over the $\mathrm{Rh} / \mathrm{Al}_{2} \mathrm{O}_{3}$. The NO fraction in the effluent gas decreased monotonically with increasing temperature from $15 \mu \mathrm{molmin}^{-1}$ at $100^{\circ} \mathrm{C}$ down to $6 \mu \mathrm{mol} \mathrm{min}^{-1}$ at $300^{\circ} \mathrm{C}$, accompanied by generation of nitrous oxide $\left(\mathrm{N}_{2} \mathrm{O}\right)$ via the partial reduction of $\mathrm{NO}$ (that is, $\left.\mathrm{NO}+1 / 2 \mathrm{CO}=1 / 2 \mathrm{~N}_{2} \mathrm{O}+1 / 2 \mathrm{CO}_{2}\right)$. The decrease in the $\mathrm{CO}$ fraction was steeper than the decrease in the $\mathrm{NO}$ fraction because $\mathrm{CO}$ was preferentially oxidized by $\mathrm{O}_{2}$ over the $\mathrm{Rh} / \mathrm{Al}_{2} \mathrm{O}_{3}$ catalyst. The effluent gas at $250{ }^{\circ} \mathrm{C}$ contained $\mathrm{NO}, \mathrm{N}_{2}$ and $\mathrm{N}_{2} \mathrm{O}$, respectively, showing that the $\mathrm{Rh} / \mathrm{Al}_{2} \mathrm{O}_{3}$ converted less than $40 \%$ of $\mathrm{NO}$ into less-toxic $\mathrm{N}_{2}$ or $\mathrm{N}_{2} \mathrm{O}$ (Fig. $4 \mathrm{f}$ ). In contrast, the $\mathrm{NO}$ fraction exposed to the mesoporous $\mathrm{Rh} / \mathrm{Al}_{2} \mathrm{O}_{3}$ (Supplementary Fig. 14) decreased as steeply as the $\mathrm{CO}$ fraction to reach a plateau of $2.5 \mu \mathrm{mol} \mathrm{min}^{-1}$ at $250^{\circ} \mathrm{C}$ (Fig. $4 \mathrm{e}$ ). The $\mathrm{N}_{2} \mathrm{O}$ fraction had an upwards trend as a result of the partial reduction of $\mathrm{NO}$, approaching to $5 \mu \mathrm{mol} \mathrm{min}{ }^{-1}$ at $250^{\circ} \mathrm{C}$ and higher temperatures. The effluent gas at $250^{\circ} \mathrm{C}$ (Fig. $4 \mathrm{f}$ ) shows that $85 \%$ of the $\mathrm{NO}$ gas 
was converted to $\mathrm{N}_{2}$ and/or $\mathrm{N}_{2} \mathrm{O}$ by the mesoporous $\mathrm{Rh}$ nanoparticles. It is clear that the mesoporous $\mathrm{Rh}$ exhibits superior activity over $\mathrm{Rh} / \mathrm{Al}_{2} \mathrm{O}_{3}$ catalyst for the remediation of $\mathrm{NO}$ in lean-burn exhaust containing high concentrations of $\mathrm{O}_{2}$ (Further discussion is shown in Supplementary Fig. 15.)

\section{Discussion}

The conformational state of the dissolved metal ions in the precursor solution depends sensitively on the interaction between the micelles and metal ions, which impacts the templated formation of mesoporous metal structure ${ }^{53,54}$. To understand the conformation state of $\mathrm{Rh}$ ions, the precursor solutions containing the PEO- $b$-PMMA micelles and $\mathrm{Na}_{3} \mathrm{RhCl}_{6}$ were studied with ultraviolet-visible (UV-VIS) absorption spectroscopy. The spectra (ii) and (iv) in Fig. 3d display peaks characteristic of $\mathrm{Na}_{3} \mathrm{RhCl}_{6}$ at around $390 \mathrm{~nm}\left({ }^{1} \mathrm{~A}_{1 \mathrm{~g}}{ }^{1} \mathrm{~T}_{1 \mathrm{~g}}\right.$, spin allowed) and $488 \mathrm{~nm}\left({ }^{1} \mathrm{~A}_{1 \mathrm{~g}}{ }^{1} \mathrm{~T}_{2 \mathrm{~g}}\right.$, spin allowed) and a weakly observed shoulder at $650 \mathrm{~nm}\left({ }^{1} \mathrm{~A}_{1 \mathrm{~g}^{-}}\right.$ ${ }^{3} \mathrm{~T}_{1 \mathrm{~g}}$, spin forbidden), matching a typical $d-d$ transition of $\mathrm{Rh}^{3}+$ ions. A previous study shows that the $\left[\mathrm{RhCl}_{6}\right]^{3-}$ ion should have corresponding signals at 411,518 and $680 \mathrm{~nm}$ in principle ${ }^{55}$. The UV-VIS absorption spectrum of $\mathrm{Na}_{3} \mathrm{RhCl}_{6}$ (Supplementary Fig. 16) dissolved in pure DMF (in the absence of water) also supports the previous demonstration that $\left[\mathrm{RhCl}_{6}\right]^{3-}$ ions have signals at $411 \mathrm{~nm}, 518 \mathrm{~nm}$, indicating solvent does not have a huge effect the absorption spectrum of $\mathrm{Na}_{3} \mathrm{RhCl}_{6}$. On the other hand, the UV-VIS absorption spectrum of $\left[\mathrm{Rh}\left(\mathrm{H}_{2} \mathrm{O}\right)_{6}\right]^{3+}$ should have corresponding peaks at 311 and $396 \mathrm{~nm}^{55}$. This large blueshift is due to water being a $\sigma$-donor only ligand, whereas $\mathrm{Cl}^{-}$ions are both $\sigma$ - and $\pi$-donors and weak field ligands. Thus, the peak positions at 390 and $488 \mathrm{~nm}$ observed in Fig. $3 \mathrm{~d}$ are located between the $\left[\mathrm{RhCl}_{6}\right]^{3-}$ ion $(411 \mathrm{~nm}, 518 \mathrm{~nm})$ and the $\left[\mathrm{Rh}\left(\mathrm{H}_{2} \mathrm{O}\right)_{6}\right]^{3+}$ $(311 \mathrm{~nm}, 396 \mathrm{~nm})$, indicating there is a partial ligand exchange between $\mathrm{H}_{2} \mathrm{O}$ and $\mathrm{Cl}^{-}$in the coordination sphere of the $\mathrm{Rh}^{3+}$ species. This is important because the proposed ligand exchange can modify the charge of the $\mathrm{Rh}$ (III) complex in solution (from $3-$ to $3+$ depending on the number of water molecules in the coordination sphere). Since the observed blueshift is small it is likely that the majority of $\mathrm{Cl}^{-}$ions are in the coordination sphere and the complex is negatively charged $\left(\left[\mathrm{Rh}\left(\mathrm{H}_{2} \mathrm{O}\right)_{3-x} \mathrm{Cl}_{6-x}\right]^{(3-x)-}\right)$.

We hypothesized that the $\mathrm{Na}_{3} \mathrm{RhCl}_{6}$ crystals are dissolved into $\mathrm{Na}^{+}$and $\left[\mathrm{Rh}\left(\mathrm{H}_{2} \mathrm{O}\right)_{3-x} \mathrm{Cl}_{6-x}\right]^{(3-x)-}$ ion complexes. The $\mathrm{Rh}$ species interacts with the micelles through hydrogen bonding, ion-dipole interaction as well as water species that are influenced by the ions (anionic and cationic complex species) on the ethylene oxide surface of the micelles. These interactions collectively enhance the concentration of $\mathrm{Rh}$ complexes around the micelles and further drive the reaction process. Moreover, we consider that some of the $\left[\mathrm{Rh}\left(\mathrm{H}_{2} \mathrm{O}\right)_{3-x} \mathrm{Cl}_{6-x}\right]^{(3-x)}-$ species exist as free ions in solution as well as in the hydrophilic domains of the PEO- $b$-PMMA micelles. Since the micelles are relatively large, they can support a lot of Rh(III) species within the EO shells. Reduction of $\mathrm{Rh}$ species in close vicinity to the micelles, combined with PEO-Rh metal interactions, help assemble and cement the mesostructured $\mathrm{Rh}$ nanoparticles.

To directly observe this growth process, intermediate products at different reaction times were investigated with TEM (Supplementary Fig. 17). At the earliest stages of the reaction, tiny $\mathrm{Rh}$ nanocrystals were observed in the precursor solution, which were likely stabilized by the EO chains of the micelles. As the reaction proceeded, the tiny crystals grew larger along with the spherical PEO-b-PMMA micelles. At this point the mesoporous structure started to appear. After $75 \mathrm{~min}$, the interconnected mesoporous architecture of the $\mathrm{Rh}$ nanoparticles began to form close-packed micelles. Beyond this time, no significant change in the shape and pore structure was observed, except that the size of the particles increased. The progress of $\mathrm{Rh}$ reduction can also be visually observed via the colour change of the reaction solution, as shown in Supplementary Fig. 18. The solution begins as red solution of molecular precursors that turn brown and then progressively black as the Rh is converted into optically lossy Rh metal. The combination of TEM and optical results supports the formation mechanism based on a chemical reduction process.

We have demonstrated the first synthesis of mesoporous $\mathrm{Rh}$ nanoparticles using chemical reduction on a soft template. The formation mechanism indicates that the dissolved metal ions coordinate to the micelle surface and assist in the nucleation and growth of the Rh metal. These mesoporous Rh nanoparticles have high surface area with abundant low-coordination atoms and surprisingly exhibit great thermal stability. As a result, the mesoporous $\mathrm{Rh}$ nanoparticles have superior electrocatalytic performance in the MOR compared to commercial Rh catalyst. These nanoparticles also exceed the performance of commercial $\mathrm{Rh}$ catalyst for NO remediation of automobile exhaust under lean-burn conditions. We believe that the soft-templating route to mesoporous materials is a robust platform to prepare various kinds of mesoporous metallic nanoparticles and nanostructured films with uniform porous architectures. Our approach applies simple solution chemistry methods that are different in concept from traditional soft-templating and hard-templating approaches. We believe the simplicity and ease of the method will enable better utilization of rare metals in industrially relevant catalytic reactions.

\section{Methods}

Preparation of mesoporous Rh nanoparticles. The synthesis of mesoporous $\mathrm{Rh}$ nanoparticles is based on a wet chemical reduction process. In a typical synthesis, $5 \mathrm{mg}$ of poly(ethylene oxide)- $b$-poly(methyl methacrylate)

$\left(\mathrm{PEO}_{(10500)}-b\right.$-PMMA $\left.(18000)\right)$ was completely dissolved in $0.6 \mathrm{ml} \mathrm{N}, \mathrm{N}-\mathrm{DMF}$. Then, $0.4 \mathrm{ml}$ of deionized water, $1 \mathrm{ml}$ of aqueous $40 \mathrm{mM} \mathrm{Na}_{3} \mathrm{RhCl}_{6}$, and $1 \mathrm{ml}$ of aqueous $100 \mathrm{mM}$ AA were added to the above DMF solution in sequence, resulting in a transparent light-brown coloured solution. The reaction solution was kept in water bath for $12 \mathrm{~h}$ at $60^{\circ} \mathrm{C}$. After the solution colour changed from light-brown to completely black, the samples were collected by centrifugation at 14,000 r.p.m. for $20 \mathrm{~min}$ and the residual $\mathrm{PEO}_{(10500)}-b$ - $\mathrm{PMMA}_{(18000)}$ was removed by five consecutive washing/centrifugation cycles with acetone and water and used for characterization.

Characterization. Field emission scanning electron microscope (SEM, HITACH SU-8000) was used to observe morphology of mesoporous Rh nanoparticles with the accelerating voltage of $5 \mathrm{kV}$. High-resolution transmission electron microscopy (HRTEM, JEOL JEM-2100F) operated at $200 \mathrm{kV}$ was used to investigate the interior structure of the mesoporous nanoparticles. The samples for TEM and HRTEM measurements were prepared by depositing a drop of the diluted colloidal suspension on a TEM grid. Powder X-ray diffraction measurements were conducted on a Smart lab X-ray diffractometer (RIGAKU) at a scanning rate of $1 \mathrm{deg} \mathrm{min}^{-1}$ with a $\mathrm{Cu} \mathrm{K} \alpha$ radiation $(40 \mathrm{kV}, 30 \mathrm{~mA})$ source. Small-angle X-ray scattering (SAXS) measurements (Rigaku NANO-Viewer) were used to evaluate the pore-to-pore distance. The SAXS instrument used a $\mathrm{Cu} \mathrm{K} \alpha$ radiation $(40 \mathrm{kV}$, $30 \mathrm{~mA}$ ) source with a camera length at $700 \mathrm{~mm}$. SANS measurements were performed at the Australian Nuclear Science and Technology Organisation on the Quokka instrument. Neutrons of $5 \AA$ wavelength were used with sample to detector distances of 8 and $1.3 \mathrm{~m}$. Samples were corrected for background measurements and placed on an absolute scale using standard procedures.

Electrochemical measurement. Electrochemical investigations were performed using a CHI 842B electrochemical analyzer (CHI Instrument, USA) to perform cyclic voltammograms, and chronoamperometric curves (CA) for mesoporous $\mathrm{Rh}$ nanoparticles and commercially available $\mathrm{Rh}$ black $(\mathrm{Rh} / \mathrm{B})$. The three-electrode cell consists of a reference electrode (saturated calomel electrode, SCE), a counter electrode (Pt wire) and a working electrode (glassy carbon electrode, GCE). The modified GCE was coated with the mesoporous Rh sample $(5.0 \mu \mathrm{g})$ and dried at room temperature. Then, $5.0 \mu \mathrm{l}$ of Nafion $(0.05 \mathrm{wt} \%)$ was coated on the surface of the modified GCE and dried before electrochemical experiments. Prior to CO stripping measurements, the GCE modified with the mesoporous Rh sample was electrochemically activated by potential cycling between $-0.4 \mathrm{~V}$ and $+0.8 \mathrm{~V}$ (versus SCE) in $0.5 \mathrm{M} \mathrm{H}_{2} \mathrm{SO}_{4}$ until the obtained CVs became characteristic of a clean Rh electrode. After that, $0.5 \mathrm{M} \mathrm{H}_{2} \mathrm{SO}_{4}$ solution with GCE was purged by $\mathrm{CO}$ 
gas for $20 \mathrm{~min}$, then was purged by using $\mathrm{N}_{2}$ gas for $20 \mathrm{~min}$ to removal of extra $\mathrm{CO}$ gas in solution. Methanol electro-oxidation measurements were performed in a solution of $1 \mathrm{M} \mathrm{KOH}$ solution containing $1 \mathrm{M}$ methanol at a scan rate of $50 \mathrm{mV} \mathrm{s}^{-1}$.

NO remediation measurement. Alumina-supported Rh nanoparticles $\left(\mathrm{Rh} / \mathrm{Al}_{2} \mathrm{O}_{3}\right.$, Aldrich, $\mathrm{Rh}$ loading $\left.=5 \mathrm{wt} \%\right)$ were used as the control. An aliquot of $5 \mathrm{mg}$ of the mesoporous $\mathrm{Rh}$ nanoparticles was mixed with $95 \mathrm{mg}$ of $\mathrm{Al}_{2} \mathrm{O}_{3}$ powder to adjust the apparent $\mathrm{Rh}$ loading to that of the control catalyst. Each of the prepared mesoporous $\mathrm{Rh} / \mathrm{Al}_{2} \mathrm{O}_{3}$ mixture and the control $\mathrm{Rh} / \mathrm{Al}_{2} \mathrm{O}_{3}$ was subjected to a steady flow of simulated exhaust containing equimolar amounts of NO, oxygen $\left(\mathrm{O}_{2}\right)$, carbon monoxide $(\mathrm{CO})$ and argon $(\mathrm{Ar})$ gas (volume ratio $=$ $\mathrm{NO}: \mathrm{O}_{2}: \mathrm{CO}: \mathrm{Ar}=1: 0.5: 1: 97.5$; space velocity $=30,000$ per $\left.1 \mathrm{~h}\right)$ at different temperatures from room temperature to $300{ }^{\circ} \mathrm{C}$. The chemical composition of the effluent gas was analysed with a Fourier transform infrared spectrometer (FTIR, Shimadzu Prestige 21) equipped with a gas cell.

Data availability. All relevant data that support this study are available within the paper and its Supplementary Information file, or from the corresponding authors upon request.

\section{References}

1. Malgras, V. et al. Nanoarchitectures for mesoporous metals. Adv. Mater. 28, 993-1010 (2016).

2. Li, W., Liu, J. \& Zhao, D. Mesoporous materials for energy conversion and storage devices. Nat. Rev. Mater. 1, 16023 (2016).

3. Zhu, C., Du, D., Eychmüller, A. \& Lin, Y. Engineering ordered and nonordered porous noble metal nanostructures: synthesis, assembly, and their applications in electrochemistry. Chem. Rev. 115, 8896-8943 (2015).

4. Guan, B. Y., Yu, L. \& Lou, X. W. Formation of asymmetric bowl-like mesoporous particles via emulsion-induced interface anisotropic assembly. J. Am. Chem. Soc. 138, 11306-11311 (2016).

5. Ji, X. et al. Nanocrystalline intermetallics on mesoporous carbon for direct formic acid fuel cell anodes. Nat. Chem. 2, 286-293 (2010).

6. Qiao, Z. A. et al. Controlled synthesis of mesoporous carbon nanostructures via a 'silica-assisted' strategy. Nano Lett. 13, 207-212 (2013).

7. Lin, T. et al. Nitrogen-doped mesoporous carbon of extraordinary capacitance for electrochemical energy storage. Science 350, 1508-1513 (2015).

8. Poyraz, A. S., Kuo, C.-H., Biswas, S., King'ondu, C. K. \& Suib, S. L. A general approach to crystalline and monomodal pore size mesoporous materials. Nat. Commun. 4, 2952 (2013).

9. Zhang, P. et al. Mesoporous $\mathrm{MnCeO}_{\mathrm{x}}$ solid solutions for low temperature and selective oxidation of hydrocarbons. Nat. Commun. 6, 8446 (2015).

10. Wang, X. et al. Synthesis of ordered mesoporous silica with tunable morphologies and pore sizes via a nonpolar solvent-assisted stöber method. Chem. Mater. 28, 2356-2362 (2016).

11. Kao, K.-C., Lin, C.-H., Chen, T.-Y., Liu, Y.-H. \& Mou, C.-Y. A general method for growing large area mesoporous silica thin films on flat substrates with perpendicular nanochannels. J. Am. Chem. Soc. 137, 3779-3782 (2015).

12. Wang, M. et al. An interface-directed coassembly approach to synthesize uniform large-pore mesoporous silica spheres. J. Am. Chem. Soc. 136, 1884-1892 (2014).

13. Niu, D. et al. Monodispersed and ordered large-pore mesoporous silica nanospheres with tunable pore structure for magnetic functionalization and gene delivery. Adv. Mater. 26, 4947-4953 (2014).

14. Zhang, F., Liang, C., Wu, X. \& Li, H. A nanospherical ordered mesoporous lewis acid polymer for the direct glycosylation of unprotected and unactivated sugars in water. Angew. Chem. Int. Ed. 53, 8498-8502 (2014).

15. Liu, J. et al. A facile soft-template synthesis of mesoporous polymeric and carbonaceous nanospheres. Nat. Commun. 4, 2798 (2013).

16. Liu, S. et al. Patterning two-dimensional free-standing surfaces with mesoporous conducting polymers. Nat. Commun. 6, 8817 (2015).

17. Akbar, S., Elliott, J. M., Rittman, M. \& Squires, A. M. Facile production of ordered 3D platinum nanowire networks with 'single diamond' bicontinuous cubic morphology. Adv. Mater. 25, 1160-1164 (2013).

18. Huang, $\mathrm{X}$. et al. A facile strategy to $\mathrm{Pt}_{3} \mathrm{Ni}$ nanocrystals with highly porous features as an enhanced oxygen reduction reaction catalyst. Adv. Mater. 25, 2974-2979 (2013).

19. Ge, J. et al. Ordered porous Pd octahedra covered with monolayer Ru atoms. J. Am. Chem. Soc. 137, 14566-14569 (2015).

20. Gu, D. et al. Highly ordered mesoporous cobalt-containing oxides: structure, catalytic properties, and active sites in oxidation of carbon monoxide. J. Am. Chem. Soc. 137, 11407-11418 (2015).

21. Warren, S. C. et al. Ordered mesoporous materials from metal nanoparticle-block copolymer self-assembly. Science 320, 1748-1752 (2008).
22. Ren, H. et al. Controllable synthesis of mesostructures from $\mathrm{TiO}_{2}$ hollow to porous nanospheres with superior rate performance for lithium ion batteries. Chem. Sci. 7, 793-798 (2016).

23. Liu, W., Lin, D., Pei, A. \& Cui, Y. Stabilizing lithium metal anodes by uniform Li-ion flux distribution in nanochannel confinement. J. Am. Chem. Soc. 138, 15443-15450 (2016).

24. Liu, K. et al. Porous Au-Ag nanospheres with high-density and highly accessible hotspots for SERS analysis. Nano Lett. 16, 3675-3681 (2016).

25. Li, C. et al. Electrochemical synthesis of mesoporous gold films toward mesospace-stimulated optical properties. Nat. Commun. 6, 6608 (2015)

26. Luo, W. et al. A micelle fusion-aggregation assembly approach to mesoporous carbon materials with rich active sites for ultrasensitive ammonia sensing. J. Am. Chem. Soc. 138, 12586-12595 (2016).

27. Kim, O.-H. et al. Ordered macroporous platinum electrode and enhanced mass transfer in fuel cells using inverse opal structure. Nat. Commun. 4, 2473 (2013).

28. Hall, A. S., Yoon, Y., Wuttig, A. \& Surendranath, Y. Mesostructure-induced selectivity in $\mathrm{CO}_{2}$ reduction catalysis. J. Am. Chem. Soc. 137, 14834-14837 (2015).

29. Shin, H. J., Ryoo, R., Liu, Z. \& Terasaki, O. Template synthesis of asymmetrically mesostructured platinum networks. J. Am. Chem. Soc. 123, 1246-1247 (2001).

30. Wang, H. et al. Shape- and size-controlled synthesis in hard-templates: sophisticated chemical reduction for mesoporous monocrystalline platinum nanoparticles. J. Am. Chem. Soc. 133, 14526-14529 (2011).

31. Attard, G. S., Goltner, C. G., Corker, J. M., Henke, S. \& Templer, R. H. Liquid-crystal templates for nanostructured metals. Angew. Chem. Int. Ed. Engl 36, 1315-1317 (1997).

32. Bartlett, P. N. \& Marwan, J. Preparation and characterization of $\mathrm{H}_{\mathrm{I}}$-e rhodium films. Microporous Mesoporous Mater. 62, 73-79 (2003).

33. Yamauchi, Y., Sugiyama, A., Morimoto, R., Takai, A. \& Kuroda, K. Mesoporous platinum with giant mesocages templated from lyotropic liquid crystals consisting of diblock copolymers. Angew. Chem. Int. Ed. 47, 5371-5373 (2008)

34. Zhang, Y. et al. Highly selective synthesis of catalytically active monodisperse rhodium nanocubes. J. Am. Chem. Soc. 130, 5868-5869 (2008).

35. Sneed, B. T. et al. Nanoscale-phase-separated Pd-Rh boxes synthesized via metal migration: an archetype for studying lattice strain and composition effects in electrocatalysis. J. Am. Chem. Soc. 135, 14691-14700 (2013).

36. Kang, Y. et al. Unexpected catalytic activity of rhodium nanodendrites with nanosheet subunits for methanol electrooxidation in an alkaline medium. Nano Res. 9, 3893-3902 (2016).

37. Lee, K. W. et al. Morphological evolution of $2 \mathrm{D}$ Rh nanoplates to $3 \mathrm{D} \mathrm{Rh}$ concave nanotents, hierarchically stacked nanoframes, and hierarchical dendrites. Nanoscale 7, 3460-3465 (2015).

38. Somorjai, G. \& Li, Y. Introduction to Surface Chemistry and Catalysis 2nd edn. (Wiley, 2010).

39. Chen, C. et al. Highly crystalline multimetallic nanoframes with threedimensional electrocatalytic surfaces. Science 343, 1339-1343 (2014).

40. Zhang, L. et al. Platinum-based nanocages with subnanometer-thick walls and well-defined, controllable facets. Science 349, 412-416 (2015).

41. Yu, N.-F. et al. Electrochemical synthesis of tetrahexahedral rhodium nanocrystals with extraordinarily high surface energy and high electrocatalytic activity. Angew. Chem. Int. Ed. 53, 5097-5101 (2014).

42. Huang, X. et al. High density catalytic hot spots in ultrafine wavy nanowires. Nano Lett. 14, 3887-3894 (2014).

43. Duan, H. et al. Ultrathin rhodium nanosheets. Nat. Commun. 5, 3093 (2014)

44. Zhao, L. et al. Single-crystalline rhodium nanosheets with atomic thickness. Adv. Sci. 2, 1500100 (2015).

45. Wen, Y.-N. \& Zhang, J.-M. Surface energy calculation of the $f c c$ metals by using the MAEAM. Solid State Commun. 144, 163-167 (2007).

46. Mittendorfer, F., Seriani, N., Dubay, O. \& Kresse, G. Morphology of mesoscopic $\mathrm{Rh}$ and Pd nanoparticles under oxidizing conditions. Phys. Rev. B 76, 233413 (2007).

47. Sneed, B. T., Kuo, C.-H., Brodsky, C. N. \& Tsung, C.-K. Iodide-mediated control of rhodium epitaxial growth on well-defined noble metal nanocrystals: synthesis, characterization, and structure-dependent catalytic properties. J. Am. Chem. Soc. 134, 18417-18426 (2012)

48. Rebholz, M., Prins, R. \& Kruse, N. Adsorption and dissociation of CO on $\mathrm{Rh}(210)$. Surf. Sci. 259, 797-803 (1991).

49. Kibsgaard, J., Gorlin, Y., Chen, Z. \& Jaramillo, T. F. Meso-structured platinum thin films: active and stable electrocatalysts for the oxygen reduction reaction. J. Am. Chem. Soc. 134, 7758-7765 (2012).

50. Jiang, B., Li, C., Imura, M., Tang, J. \& Yamauchi, Y. Multimetallic mesoporous spheres through surfactant-directed synthesis. Adv. Sci. 2, 1500112 (2015).

51. Auxilia, F. M. et al. Low-temperature remediation of NO catalyzed by interleaved $\mathrm{CuO}$ nanoplates. Adv. Mater. 26, 4481-4485 (2014).

52. Iwamoto, M. \& Hamada, H. Removal of nitrogen monoxide from exhaust gases through novel catalytic processes. Catal. Today 10, 57-71 (1999). 
53. Çelik, Ö. \& Dag, Ö. A new lyotropic liquid crystalline system: oligo(ethylene oxide) surfactants with $\left[\mathrm{M}\left(\mathrm{H}_{2} \mathrm{O}\right)_{n}\right] \mathrm{X}_{\mathrm{m}}$ transition metal complexes. Angew. Chem. Int. Ed. 40, 3800-3803 (2001).

54. Yamauchi, Y. et al. Electrochemical synthesis of mesoporous Pt-Au binary alloys with tunable compositions for enhancement of electrochemical performance. J. Am. Chem. Soc. 134, 5100-5109 (2012).

55. Wolsey, W. C., Reynolds, C. A. \& Kleinberg, J. Complexes in the rhodium(III)-chloride system in acid solution. Inorg. Chem. 2, 463-468 (1963).

\section{Acknowledgements}

This work was partly supported by an Australian Research Council (ARC) Future Fellow FT150100479), the UOW-ANSTO 2016 grant, and the AIIM-MANA 2016 grant. We are also thankful to the World Bank for partial funding of this work through a subproject of Higher Education Quality Enhancement Project (HEQEP), Complete Proposal \#2071.

\section{Author contributions}

B.J. synthesized and characterized the mesoporous $\mathrm{Rh}$ nanoparticles, Ö.D. analysed the ultraviolet-vis data, B.J., H.A. and T.I studied catalytic test, T.T. and Md.S.A.H. analysed the SEM and TEM data, K.W. studied micelle structures, C.L., Ö.D., Md.T.I. and J.H. helped to describe the formation mechanism and Y.Y. designed this work. All the authors discussed the results and participated in writing the manuscript.

\section{Additional information}

Supplementary Information accompanies this paper at http://www.nature.com/ naturecommunications

Competing interests: The authors declare no competing financial interests.

Reprints and permission information is available online at http://npg.nature.com/ reprintsandpermissions/

How to cite this article: Jiang, B. et al. Mesoporous metallic rhodium nanoparticles. Nat. Commun. 8, 15581 doi: 10.1038/ncomms15581 (2017).

Publisher's note: Springer Nature remains neutral with regard to jurisdictional claims in published maps and institutional affiliations.

\section{(c) (1)}

This work is licensed under a Creative Commons Attribution 4.0 International License. The images or other third party material in this article are included in the article's Creative Commons license, unless indicated otherwise in the credit line; if the material is not included under the Creative Commons license, users will need to obtain permission from the license holder to reproduce the material. To view a copy of this license, visit http://creativecommons.org/licenses/by/4.0/

(C) The Author(s) 2017 